\title{
DESENVOLVIMENTO DAS SIGNIFICAÇÕES DE SI EM CRIANÇAS NA PERSPECTIVA DIALÓGICO-CULTURAL ${ }^{1}$
}

\author{
Monica Roncancio Moreno² \\ Universidad Javeriana, Bogotá, Colômbia \\ Angela Maria Branco \\ Universidade de Brasília, Brasilia-DF, Brasil
}

\begin{abstract}
RESUMO. A partir da abordagem da Psicologia Cultural e da Teoria do Self Dialógico, o objetivo da pesquisa consistiu em caracterizar e analisar as significações de uma criança em fase de transição da Educação Infantil (EI) para o Ensino Fundamental (EF) relativas às suas percepções e avaliações de si. Utilizando uma metodologia qualitativa de caráter idiográfico, acompanhamos um grupo de crianças durante seu último semestre na El e os primeiros seis meses no EF, realizando observações diretas e sessões semiestruturadas diversas, devidamente filmadas, e entrevistas com pais e professores. Neste artigo analisamos o estudo de caso de Gisele, identificando três campos afetivo-semióticos (CAS) que configuram seu sistema de Self: ser versus não ser bonita, ser versus não ser inteligente e ser versus não ser amada. Estes três campos afetivo-semióticos evidenciam as fortes tensões no Self de Gisele. Com base nos dados obtidos, verificamos que a transição da El para o EF permitiu a configuração e reconfiguração de diversos campos afetivo-semióticos no sentido da transformação e equilíbrio (desenvolvimento) do sistema de Self de Gisele. Isto ocorreu mediante a emergência de novas significações de si no contexto da dinâmica no interior dos referidos campos. Evidenciamos situações de conflito e a configuração de opostos capazes de levar à síntese de novos sentidos do Self dialógico em desenvolvimento.
\end{abstract}

Palavras-chave: Psicologia Cultural; dialogismo; desenvolvimento do eu.

\section{THE DEVELOPMENT OF SELF MEANING-MAKING IN CHILDREN FROM A DIALOGIC CULTURAL PERSPECTIVE}

\begin{abstract}
Based on Cultural Psychology and the Dialogical Self Theory, the main goal of this study was to analyze the meaning making processes of a child in her transition from Preschool to Elementary School, regarding her Self-perceptions and Self-evaluations. Using a qualitative methodology with an idiographic focus, we followed a group of children during their last semester at Preschool and first semester at an Elementary School. We carried out direct observations, and semi-structured sessions, properly filmed, and interviews with the selected kids' parents and teachers. This article analyzes Gisele's case study. As a result of the empirical research, we identified three affective-semiotic fields that configure Gisele Self system: to be versus not be pretty, to be versus not be smart and to be versus not be loved. These four affective-semiotic fields highlight the tensions in Gisele self system. According to the results, the transition from Preschool to Elementary School configured and reconfigured several affective-semiotic fields towards the balance as well as the transformation (development) of Gisele Self system. The emergence of new Selfmeanings provided for the dynamics inside the fields. We demonstrate how some conflicts and the emergence of opposites may eventually lead to the synthesis of new directions in dialogical Self development.
\end{abstract}

Keywords: Cultural psychology; dialogism; self-development.

\section{DESARROLLO DE LAS SIGNIFICACIONES DE SÍ EN NIÑOS EN LA PERSPECTIVA DIALÓGICO-CULTURAL}

RESUMEN. A partir del enfoque de la psicología cultural y de la Teoría del Self Dialógico, el objetivo de la presente investigación consistió en caracterizar y analizar las significaciones de un niño en fase de transición de la Educación

\footnotetext{
1 Apoio e financiamento: Coordenação de Aperfeiçoamento de Pessoal de Nível Superior (CAPES).

2 Endereço para correspondência: Calle 42ª No. 9-59 APT 203, Bogotá-Colômbia. E-mail: monikarm83@gmail.com.
} 
Infantil-El para la Educación Básica-EB, relacionadas a sus percepciones y evaluaciones de sí. Con el uso de una metodología cualitativa de carácter ideográfico, acompañamos a un grupo de niños durante su último semestre en la El y los primeros seis meses en la EB, realizando observaciones directas y sesiones semiestructuradas diversas, debidamente filmadas, y entrevistas con padres de familia y profesores. En este artículo, analizamos el estudio de caso de Giselle, identificando tres campos afectivo-semióticos (CAS) que configuran su sistema de self: ser versus no ser bonita; ser versus no ser inteligente y ser versus no ser amada. Estos tres campos afectivo-semióticos evidencian las fuertes tensiones en el self de Giselle. Con base en los datos obtenidos, verificamos que la transición de la El para la EB permitió la configuración y reconfiguración de diversos campos afectivo-semióticos en el sentido de la transformación y el equilibrio - o sea, desarrollo - del sistema de self de Giselle. Esto ocurrió mediante la urgencia de nuevas significaciones de sí en el contexto de la dinámica en el interior de los referidos campos. Evidenciamos situaciones de conflicto y la configuración de opuestos, capaces de llevar a la síntesis de nuevos sentidos del self dialógico en desarrollo.

Palabras-clave: Psicología cultural; dialogismo; desarrollo del yo.

Um objetivo importante da Psicologia do Desenvolvimento é o estudo das mudanças ocorridas durante a trajetória de vida dos indivíduos (Zittoun, 2009). O sujeito, como ser complexo e em permanente transformação, dispõe de recursos psicológicos que lhe permitem agir sobre a realidade e mudar as suas condições. No levantamento da literatura sobre os processos de coconstrução do Self dialógico, observamos a necessidade de realizar estudos sobre a ontogênese do Self que permitam identificar e analisar os processos de mudança que ocorrem mediante a internalização ativa de significados e a dinâmica interativa do sistema de self dialógico em desenvolvimento.

$\mathrm{Na}$ perspectiva da ciência idiográfica (Valsiner \& Salvatore, 2012), este artigo pretende contribuir para uma compreensão ampla e sistêmica das dinâmicas das significações sobre si de uma criança em um momento específico de sua vida, durante o período de transição da Educação Infantil (EI) para o Ensino Fundamental (EF).

Escolhemos este período por considerar que as transições levam a reconfigurações do sistema de Self que podem ser elucidadas com o uso de diversas metodologias. Por aspectos éticos, os nomes de todos os participantes da pesquisa citados são fictícios. A criança analisada neste artigo recebeu o nome fictício de Gisele (assim como todos os outros participantes), e foi escolhida por apresentar reflexões e avaliações sobre si que permitiram delinear indicadores do fenômeno psicológico definido como desenvolvimento do Self. No estudo de caso, identificamos diferentes tipos de indicadores que evidenciaram 0 Self em desenvolvimento nesta criança (cinco a seis anos de idade), o que poderá favorecer a identificação de alguns dos possíveis catalisadores que atuam na promoção de trajetórias saudáveis para crianças em transição escolar.

\section{DESENVOLVIMENTO HUMANO NO CONTEXTO SOCIOCULTURAL}

Assumimos como plataforma teórica a perspectiva sociocultural que enfatiza o papel construtivo do sujeito e o desenvolvimento humano como um fenômeno dinâmico e complexo (Bruner, 1990/1997; Branco \& Valsiner, 1997, 2012; Rogoff, 2003/2005; Valsiner, 2007/2012), em articulação com importantes aspectos da teoria do Self Dialógico de Hubert Hermans (Hermans, 2001; Hermans \& Hermans-Kanopka, 2010). A abordagem se centra em propor o diálogo e a mútua constituição entre cultura e sujeito, reconhecendo o papel central dos fatores histórico-culturais, a singularidade dos indivíduos e o seu caráter construtivo.

A perspectiva afirma que não apenas o sujeito, mas qualquer fenômeno humano ou social tem um fundamento histórico e cultural, essencial à sua contextualização. Enfatiza o caráter coconstrutivista dos processos psicológicos e propõe a "participação ativa do sujeito na construção de seu desenvolvimento, e a existência de mecanismos de canalização cultural orientados pelos limites (constraints) presentes nos contextos socioculturais dentro dos quais se dá o desenvolvimento humano" (Branco \& Mettel, 1995, p. 15). Considerando-se o estudo do desenvolvimento do Self, o conceito 
de campos afetivo-semióticos (CAS) proposto por Valsiner (2007/2012) é muito útil e de especial interesse.

\section{Campos afetivo-semióticos (CAS)}

Os CASs têm sua origem no Modelo de Regulação Afetiva, proposto por Valsiner (2007/2012). Estes são campos de significação com qualidade afetiva que vão permitir a estabilidade relativa e o desenvolvimento dinâmico do sistema de Self. Estes campos são abrangentes e estão na base da criação de múltiplos significados e interpretações. Podemos supor que, no caso das crianças, estes campos são mais indiferenciados e a ambivalência entre os diferentes significados se instaura atravessada por uma forte tensão semiótica e afetiva (Valsiner, 2007/2012). Nos CASs funcionam os signos, que podem assumir 0 papel de mediadores ou reguladores ou promotores. Para adquirir um caráter regulador, um signo precisa de um movimento constante e generalizante que permita a sua transformação em um marcador semiótico, assumindo, desta maneira, certo poder de regulação sobre os processos de significação. Os valores são um exemplo importante de reguladores semióticos. Ao ser internalizado, um signo pode funcionar como um signo promotor de desenvolvimento quando reiteradamente atua como orientador da atividade humana (Valsiner, 2007/2012). Ele possibilita que o sujeito pense sobre o futuro e seja flexível diante de possíveis trajetórias de desenvolvimento. A característica definidora dos CAS é que em seu interior operam diferentes forças ou tensões que levam à construção permanente de novos significados. Assim, múltiplos significados ambivalentes podem existir no campo e caracterizar as significações de si de um sujeito específico. Na presente pesquisa buscamos analisar os três campos identificados no caso de Gisele, como significativos.

\section{Contribuições da Teoria do Self Dialógico}

A Teoria do Self Dialógico (TSD) proposta por Hubert Hermans e colaboradores (Hermans, 2001; Hermans \& Hermans-Konopka, 2010) surge da síntese criativa das ideias de George Mead, William James e Mikhail Bakhtin. A TSD propõe que nos indivíduos coexistem diferentes posições de Eu (I-Positions) que constituem o Self (dialógico). Estas posições dialogam ou negociam entre si de forma intencional e não intencional e podem ser inferidas a partir das múltiplas vozes presentes nas narrativas do sujeito. Hermans (2001) defende que "o Eu flutua através de diferentes posições e tem a capacidade imaginativa de dotar cada posição com uma voz e, assim, são estabelecidas as relações entre posições" (p. 248).

A partir das mobilizações do Eu (em espaços imaginários), ou mobilização das posições, são produzidos campos dinâmicos nos quais múltiplos sentidos se constroem. Nesses campos acontecem diferentes Self-negociações, Self-contradições e Self-integrações (Hermans, 2001). Estas posições de Eu habitam a dimensão interativa entre o que pode ser concebido como interno e externo, para efeito de análise, e funcionam de maneira relativamente autônoma. As posições internas são do tipo Eu-mãe, Eu-esposa, e Eu-boa aluna; já as posições externas são experimentadas como parte do ambiente e consideradas pelo individuo como relevantes desde a perspectiva das posições internas (meus filhos, meu marido, meu professor). Posições internas e externas coexistem como posições de Eu no sistema do Self e formam parte de um ambiente concebido como "meu". Importantes aspectos da Teoria do Self Dialógico podem ser integrados à perspectiva sociocultural construtivista com o uso do conceito Sistema de Self.

\section{O Sistema de Self na perspectiva sociocultural construtivista}

A partir da perspectiva sociocultural construtivista, Branco (2010) propõe que o sistema de Self se configura em função das relações sociais específicas do individuo que ocorrem nos contextos culturais dos quais participa. O sistema de Self apresentado na figura 1 mostra como as diferentes posições de Eu/self estão configuradas num momento determinado. Nesse sistema, composto por várias posições dinâmicas, o I (ou "EU") representa a dimensão do agente, e o self, a dimensão reflexiva. Tal denominação é inspirada por G. H. Mead (1934), que designou as duas facetas do "Eu” psicológico como 'l' (Eu-agente) e 'ME' (Eu-reflexivo). Por sua vez, Branco (2010) prefere denominar o Eu-reflexivo como "self", evitando o termo "Me". Múltiplas relações são estabelecidas entre as diferentes posições, compostas pelas duas dimensões mencionadas (Iposition/self-position), e essas posições podem ser mais ou menos dominantes no sistema, a depender do momento (tempo) e do contexto 
específico (espaço cultural) em que o Sistema de Self estiver atuando. Em outras palavras, o Self não é simplesmente um ponto no espaço, mas deve ser concebido como um sistema, organizado de forma dialógica, múltipla, complexa e interdependente. Neste sistema observam-se interações dialógicas interindividuais (sociais) e intraindividuais (nível interno do sujeito) que se definem mutuamente. Além disso, o sistema caracteriza-se por maior ou menor estabilidade relativa associada a um movimento dinâmico aberto à emergência de novidades e a mudanças nas relações de hierarquia dentro do sistema (Branco, 2010).

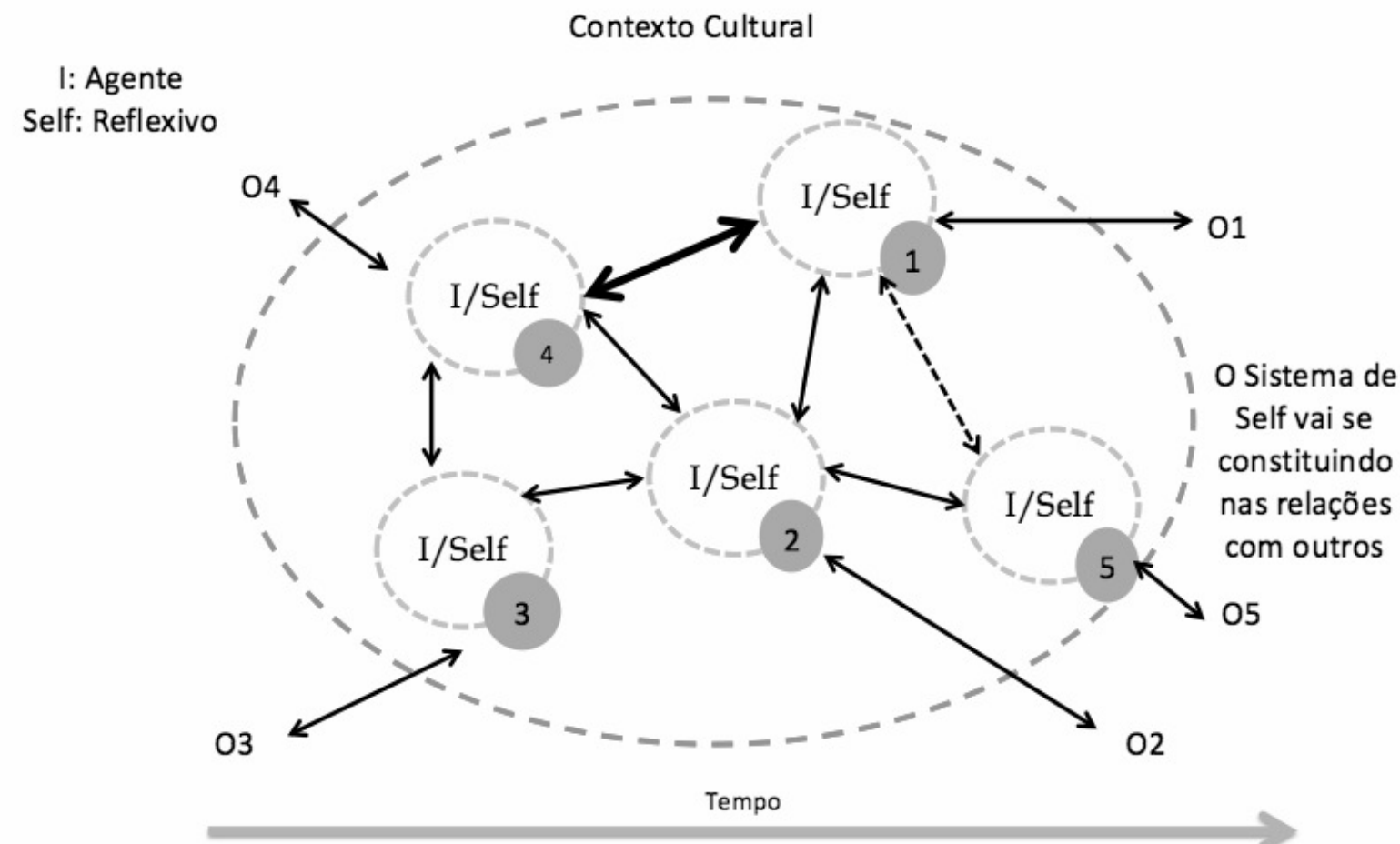

Fonte: Branco, 2010.

Figura 1. Sistema de Self -01 a O5 = o outro social específico (pessoa ou grupo)

O "outro" apresentado na figura 1 por numerais de 1 a 5 (um indivíduo ou um grupo) vai ser aquele em relação ao qual a pessoa se posiciona: a posição $\mathrm{l} / \mathrm{self} \mathrm{O} 1$ corresponde ao outro específico $\mathrm{O} 1$, e assim por diante. Esta relação de alteridade define, configura e reconfigura, de forma dinâmica e mediante processos coconstrutivos, as diferentes concepções de si que compõem o Self dialógico. Os elementos afetivos e a experiência são fundamentais nessa proposta teórica, pois são estas as dimensões que dão consistência e densidade às posições do "Eu" e permitem dar sentido à própria existência. Impregnando cada posição I/self e a cada uma delas associando-se, encontramos, então, valores correspondentes que fornecem uma relativa estabilidade ao sistema, ou seja, os valores alimentam a configuração de diferentes posições $I /$ self, pois são muito carregados de afeto, portanto são também mais resistentes a mudanças (Branco, Branco, \& Madureira, 2008); no entanto o caráter dinâmico do sistema permanece, e, como em todo sistema dinâmico desenvolvimental (Ford \& Lerner, 1992), observa-se o movimento contínuo entre estabilidade e mudança.

Assumindo a proposta de Branco (2010), propomos que o desenvolvimento do Self pode ser estudado a partir das interações do sujeito com aspectos diferenciados da sociocultura, e este desenvolvimento pode ser capturado tanto na narrativa, quanto na observação de interações relevantes do sujeito. Nas últimas décadas o tema do desenvolvimento humano vinculado aos processos de transição, em qualquer etapa da vida, tem recebido especial interesse (Mattos, 2013; Zittoun, 2009). Estes estudos focalizam as transformações, em nível subjetivo, que acontecem na trajetória de vida dos indivíduos ao longo do seu desenvolvimento. 
Na presente pesquisa nos debruçamos sobre a problemática específica das transições para estabelecer um pano de fundo que permita identificar a maneira como uma criança de cinco a seis anos de idade constrói avaliações de si mesma durante o período de transição da Educação Infantil (El) para o Ensino Fundamental (EF).

A escolha desse período para estudar as significações de si foi feita levando-se em consideração pesquisas sobre o tema que informam sobre as possíveis transformações (e até rupturas) acontecidas nesse momento da vida das crianças (Amaral, 2008; Corsaro \& Molinari, 2005; Motta \& Kramer, 2010). Ao se deparar com um mundo novo na Escola Fundamental, caracterizado por uma cultura letrada $e$ diferente do universo da El (denominado jardim de infância até pouco tempo), os posicionamentos das crianças sobre si e sobre o mundo tendem a se mobilizar, o que promove reconfigurações em seu sistema de Self. Isto traz consigo uma dinâmica de interesse fundamental para ser estudada pela Psicologia do Desenvolvimento.

\section{MÉTODO}

Ao assumir como objetivo do estudo a análise das significações de si de uma criança ao longo da transição da El para o EF, o passo seguinte é buscar as diferentes configurações do Self que podem estar em construção na infância. Deparamo-nos, assim, com o desafio metodológico e prático de procurar com a criança, no contexto do dia a dia, as suas visões sobre o mundo e, especialmente, sobre elas mesmas enquanto seres em desenvolvimento.

Os métodos variados utilizados nesta pesquisa são típicos de uma metodologia qualitativa, e permitiram obter indícios empíricos da qualidade das relações socioafetivas da criança no contexto de sua experiência educacional com colegas e adultos. Também permitiram a obtenção de indicadores de como a criança selecionada para o estudo de caso percebe e avalia o seu envolvimento nas atividades da escola e na família. Adotamos como eixo metodológico o método idiográfico (Valsiner \& Salvatore, 2012), o qual permite potencializar o valor da metodologia qualitativa. O método idiográfico está baseado na premissa de que todo fenômeno estudado é único. Com este método é possível construir generalizações com base na análise dos processos identificados nos estudos de caso, a qual gera conhecimentos que podem ser aplicados a novos casos com características similares. As relações presentes no fenômeno estudado são sempre complexas e emergem em um tempo irreversível. O estudo de caso, método ideográfico por definição, permite pesquisar os fenômenos psicológicos de maneira holística, contextual e em profundidade. Uma de suas vantagens é a possibilidade de triangulação entre as fontes de dados, isto é, os diferentes procedimentos adotados no estudo. Sendo assim, o estudo de caso e o método idiográfico se constituem como a melhor opção para investigar os processos de desenvolvimento, pois consideram o caráter dinâmico e complexo do individuo.

Optou-se pela utilização de diferentes procedimentos (triangulação), os quais permitiram identificar, analisar e compreender as significações de si de Gisele em sua transição da El para o EF. O estudo empírico foi desenvolvido em duas fases. A Fase I se refere à $\mathrm{El}$, e a Fase II, ao semestre seguinte, no EF. Os procedimentos ocorreram durante o último semestre de Gisele na El e o seu primeiro semestre no EF, com a participação de suas professoras em ambas as instituições, além de seus pais. As duas instituições eram públicas e estavam localizadas no DF.

\section{Participante}

Participaram do estudo uma menina de cinco anos de idade (no início da pesquisa), seus pais e professoras na El e no EF.

\section{Procedimentos}

Foram desenvolvidos múltiplos procedimentos metodológicos para a realização das fases I e II. $\mathrm{Na}$ fase I a pesquisadora realizou observações com o objetivo de identificar a rotina diária das crianças e melhor entender o funcionamento da instituição de El. A pesquisadora pediu à professora que identificasse as crianças que se adaptariam mais ou menos facilmente ao EF. Gisele foi apontada pela professora como uma das crianças que iriam se adaptar mais facilmente ao EF e cujos pais, além disso, teriam disponibilidade para participar da pesquisa durante o período de um ano. 
A aproximação da pesquisadora com Gisele foi realizada com a mediação de um diário de desenhos, caderno no qual a menina desenhava semanalmente. Ela foi entrevistada duas vezes por mês, sendo a conversa mediada pelos desenhos feitos no diário. Outros procedimentos adotados foram a entrevista individual e uma brincadeira com bonecos de pano em duplas (Gisele brincou com o parceiro Anderson, também participante da pesquisa). A brincadeira com bonecos teve como objetivo permitir a expressão de sentimentos, crenças, valores e ideias sobre o ambiente escolar. A pesquisadora entregou cinco bonecos com diferentes características raciais (pardo, branco, negro), expressões faciais (triste, feliz, bravo) e alguns objetos típicos de uma instituição de El.

No final do ano letivo foram realizadas entrevistas com os pais e a professora, visando explorar quais as concepções que os adultos significativos tinham sobre Gisele e quais ideias e expectativas estes tinham sobre o processo de transição. Todos os procedimentos foram gravados em áudio e todas atividades com as crianças foram filmadas.

$\mathrm{Na}$ fase II, no EF, foram desenvolvidos procedimentos similares aos realizados na El.

\section{Instrumentos}

Durante o desenvolvimento de toda a pesquisa foram utilizados nove roteiros para as entrevistas e as atividades estruturadas. Foram utilizados duas câmeras de vídeo, dois laptops, um tripé, brinquedos, bonecos e folhas de papel. A análise dos dados deu-se com base na transcrição integral de todas as entrevistas e atividades semiestruturadas realizadas nas fases I e II. Depois, procurou-se identificar os episódios que tivessem relação com avaliações e reflexões sobre si da criança, os quais foram posteriormente analisados.

\section{RESULTADOS E DISCUSSÃO}

Gisele é filha de pais com formação superior, ambos brancos, mas apenas o pai é loiro de olhos claros. Este dado revelou-se importante ao longo do estudo. As características físicas da menina são mais parecidas com as da mãe, de cabelo e olhos escuros, e sua irmã mais velha, Bárbara, é parecida com o pai: uma menina loira, branca e de olhos claros. Após transcrevermos o material e analisarmos o conjunto das informações, obtivemos indicadores da existência de três CASs que, ao que tudo indica, orientavam as significações de si de Gisele.

\section{Campos afetivo-semióticos (CAs) em tensão}

Os três CASs que configuram as significações de si de Gisele foram "ser versus não ser" (1) bonita, (2) inteligente e (3) amada.

Esses CASs evidenciam fortes tensões no sistema de Self da criança e se configuram de acordo com determinados significados que circulam nos diferentes contextos onde a criança se desenvolve (família, escola, igreja). Nos trechos a seguir discutimos como alguns significados são coconstruídos pela criança na El e no EF, e como a transição de um para outro contexto parece gerar novidade, produzindo uma espécie de coexistência do novo com o velho significado.

\section{Ser versus não ser bonita: manutenção de significados}

Observou-se, ao longo do ano de pesquisa, a manutenção/continuidade da tensão entre ser e não ser bonita associada à reiterada demanda de Gisele por um reconhecimento social de sua beleza. O significado do que é "bonito" se encontra relacionado à mediação que os outros significativos fazem do que é aceito como bonito ou feio pela cultura. Os outros sociais são encarregados de dar ou não valor a determinadas características físicas. Os adultos ao redor de Gisele ofereciam alguns marcadores - signos ou insígnias - (Mattos, comunicação pessoal em 10/07/2013) do que era ou não bonito, mais ou menos bonito, sendo a beleza altamente valorizada nos grupos sociais mais próximos (escola, igreja). No caso particular de Gisele, circulavam significados de que "o bonito é branco, de cabelo loiro e olhos claros", as características que correspondem a seu pai e sua irmã mais velha, Bárbara. Estes indicadores surgiram nas entrevistas com os pais da menina, os quais mencionaram recorrentemente que Bárbara chamava muito a atenção das pessoas pela cor dos olhos e o cabelo. Os adultos dos grupos sociais que os pais frequentavam admiravam esta característica da irmã na frente de Gisele, muitas vezes perguntando o porquê da diferença entre os traços das duas meninas, e diante disso Gisele demonstrava tristeza. Também comentaram que algumas vezes Gisele dissera à mãe que desejava ter as cores do 
cabelo e dos olhos iguais às de Bárbara, perguntando também por que ela não era tão bonita quanto a irmã, demonstrando tristeza.

Em uma das entrevistas Gisele comentou que Bárbara era a criança mais bonita da sala (Bárbara estudava no terceiro ano na mesma escola), e em alguns momentos na escola, quando estava próxima da irmã, Gisele pegava no cabelo de Bárbara e falava para a pesquisadora: "Ela não é linda, tia? Não é a menina mais bonita da escola?"; mas durante uma entrevista individual, ao lhe ser perguntado de novo pela pesquisadora qual era a criança mais bonita da escola, Gisele respondeu se apontando várias vezes com segurança: "Eu! É! Eu acho eu mesma bonita!'. Durante a escola de bonecos Gisele pegou a boneca e disse: "Eu sou bonita! Eu sou bonita!' (fazendo a voz da boneca e rindo). Outro indicador relacionado a este CAS emergiu durante as observações em sala de aula, quando vimos Gisele como centro de elogios de seus coleguinhas, liderando brincadeiras nas quais se colocava como menina bonita.

Nos trechos anteriores apresentamos alguns indicadores que informam sobre a ambivalência sentida por Gisele com relação à beleza. Em nossa perspectiva, toda significação é marcada por uma tensão semiótica. Neste caso, Gisele coconstruiu a autorreferência de ser $x$ não ser bonita baseada no sistema de valores da cultura, em especial de seus familiares. Tudo indica a existência de um padrão de beleza na cultura que permeia a família da menina, o qual é preenchido por sua irmã mais velha: belas são as pessoas bem brancas, loiras e de olhos claros. Com base nas entrevistas e observações, concluímos que a significação de beleza foi construída no imaginário de Gisele a partir das sugestões familiares e sociais, tão difundidas na cultura brasileira. Sua mãe, durante a entrevista, é consciente da situação, pois a menina tem comentado com ela seu desejo de ter a cor da pele da irmã, e diz se esforçar para convencer Gisele de que ela é linda, apesar de ser diferente do padrão de beleza de Bárbara e daquele sugerido pela mídia. Este padrão parece, de fato, predominar entre os membros da sociedade: ser branco, loiro e de olhos claros é ser belo, desejável. É provável, assim, que a irmã mais velha represente para Gisele o padrão de beleza ideal, o qual ela gostaria de ter.

Gisele possivelmente está se questionando se é bela ou não, e esses questionamentos parecem orientar de forma permanente os relacionamentos da menina no ambiente escolar e na família, nas brincadeiras e falas que observamos ao longo do ano. Com relação à irmã, Gisele não se permite mostrar raiva ou qualquer emoção que indique rivalidade ou competição; pelo contrário, todas as suas referências a Bárbara são feitas com muito carinho, mencionando que ela é sua melhor amiga e cuidadora, enfim, Bárbara é o modelo a ser seguido.

Vemos aqui uma tensão entre o que para Gisele significa com ser "bonita" em sua fala e as referências feitas por sua mãe sobre ela querer ter a pele e o cabelo iguais aos da irmã, demonstrando tristeza por não ser tão bonita. Não se achar bonita aparece várias vezes nos comentários dos pais na entrevista, especialmente quando falam da comparação que fazem os outros entre as duas irmãs. A menina se posiciona diante de suas colegas como uma criança bonita (através de gestos e ações nas brincadeiras), diz ser uma menina "linda" (em sua própria narrativa), mas este processo de coconstrução do que é belo está atravessado por uma série de incertezas e ambivalências que parecem formar um CAS poderoso, mas pouco definido. As orientações sobre o que é bonito ou não são fornecidas pela cultura: em nível mais geral, pela mídia, mas principalmente pela família e escola. Ao mesmo tempo, tais orientações são interpretadas pela menina com relação a si mesma, e assim a ambivalência prevalece.

Finalmente, podemos afirmar que o CAS ser versus não ser bonita permite a coexistência dinâmica de diferentes significações no âmbito do Self, garantindo a manutenção e o desenvolvimento do sistema de Self de Gisele com vista ao futuro. É possível que o significado atribuído a beleza seja posteriormente generalizado e se converta em um campo afetivo hipergeneralizado (Valsiner, 2007/2012), a orientar as motivações, ações e interações de Gisele ao longo da ontogênese. A depender de qual alternativa prevalecer, este campo terá mais ou menos poder regulador no sistema, e tenderá para uma significação de si mais ou menos satisfatória em termos de autoestima.

\section{Ser versus não ser inteligente: reconfiguração e emergência da novidade}

Outra das significações de si analisadas foi ser versus não ser inteligente. Tanto na fala com 
a pesquisadora como em alguns momentos na sala de aula, Gisele se move diante dessa aparente contradição. Em seu ambiente familiar, ser inteligente tem um alto valor, especialmente para o pai da menina, e este destaca a inteligência da filha Bárbara em contraste com o atraso intelectual que atribui a Gisele. Talvez esse atraso intelectual esteja relacionado ao remédio que a menina toma por conta de uma convulsão que teve quando tinha oito meses de idade. $\mathrm{Na}$ entrevista individual, Gisele disse claramente que era "a mais inteligente e a menos inteligente da sala". A coexistência explícita das duas posições aparentemente contraditórias entre si mostra a presença de significações ambivalentes e a qualidade dinâmica do sistema de CAS. Este é, para Gisele, outro campo gerador de tensões e mal definido, pois existe aí uma permanente reconfiguração desta avaliação de si.

$\mathrm{Na} \mathrm{El}$ Gisele consegue cumprir com as expectativas da professora e terminar, muitas vezes, antes dos colegas. Nas observações em sala de aula conseguimos evidenciar o papel explícito que a professora desempenha como mediadora da avaliação "mais inteligente": a professora elogia os trabalhos feitos pela menina, e quando Gisele não está muito interessada no dever, ela a incentiva com comentários do tipo "Você pode sim, porque você é uma criança capaz de fazer, você é uma criança muito inteligente, olha só o seu trabalhinho tudo caprichado!". Especialmente no caso de trabalhos de desenho, a competência de Gisele era destacada com satisfação pela professora diante da turma. Desta maneira, a professora cumpre o papel de agente catalisador (Mattos, comunicação pessoal em 10/07/2013) que antecipa para a menina um posicionamento de pessoa capaz e inteligente, que a própria Gisele não conseguia ter de si mesma diante do poder da voz paterna, que a considera "atrasada para a sua idade" (pai de Gisele durante a entrevista).

Não obstante, a avaliação como "menos inteligente" durante o período da El parece ter tido maior carga afetiva do que a avaliação "mais inteligente" referida pela professora. Afinal, ser menos inteligente corresponde à internalização das vozes do pai e da mãe, com maior dominância para a voz do pai. Na entrevista com os pais emergiram concepções e crenças sobre a menina, e o pai disse acreditar que Gisele tinha um problema em seu desenvolvimento.
Segundo ele, a menina “... resiste ao aprendizado, com dificuldades de memorização, falta de interesse, não tem capacidade para assimilar os conhecimentos do primeiro ano, [é] desorganizada". Por outro lado, a mãe também manifesta que "Gisele tem um atraso de desenvolvimento de pelo menos dois anos, ela teve dificuldades na linguagem, dificuldades para caminhar". Ambos os pais, durante a entrevista, compararam com frequência o desenvolvimento das duas filhas, sempre favorecendo Bárbara. Podemos supor, com base na narrativa de ambos, que eles enviavam contínuas mensagens para Gisele manifestando sua insatisfação com o desempenho escolar da menina - mensagens em nível explícito, mas principalmente, mensagens implícitas, sutis, metacomunicativas (Branco \& Valsiner, 2004). Tais valores e convicções dos pais, externalizados diante de Gisele - de acordo com as informações fornecidas na entrevista com os pais - possivelmente levaram a menina a internaliza-los e, posteriormente, reconstruir sua própria visão sobre si mesma: "eu sou menos inteligente às vezes..." (indicador emergente na entrevista com a menina). É o confronto entre a qualidade de seu desempenho, elogiado na escola mas desqualificado pelos pais, que a comparam com a irmã.

Sua autoavaliação se reconfigura permanentemente, dependendo do outro social e do contexto em que se insere. As conquistas de Gisele são dificultadas e não reconhecidas pela percepção negativa dos pais sobre as competências da filha, o que produz um CAS no sistema de Self caracterizado por zonas de muita ambivalência e tensão. Durante o acompanhamento da menina no período de transição, observamos que a questão da inteligência foi se constituindo como um signo muito importante para o desenvolvimento da dinâmica de seu Self dialógico, passando até a prevalecer hierarquicamente sobre o CAS relativo a "ser bonita".

$O$ ingresso de Gisele no EF foi marcado por choro permanente e recusa a ir para a escola. Em momentos diversos escutamos Gisele se chamar de "burra" (indicadores emergentes em observações em sala de aula); mas com o tempo ela passou a dizer "Eu sou burra mas estou aprendendo". Essas duas significações de si, que aparentemente se contrapõem, foram sendo articuladas no EF, sofrendo uma rápida transformação nos primeiros três meses do 
primeiro ano de escola. Essas transformações encontram-se possivelmente relacionadas ao processo adaptativo ao EF, no qual a professora teve um papel muito importante, incentivando sempre Gisele e destacando a suas capacidades, assumindo assim um papel do outro que se antecipa a suas competências (Ferraz, 2008; Mattos, comunicação pessoal em 10/07/2013).

Nas primeiras semanas de aula no EF Gisele começou a se tornar mais interessada pelo desenho, mas isso, possivelmente, teve origem em outro aspecto importante: as brincadeiras no contexto do EF diminuíram, pois o tempo ou espaço para brincar era pouco e as brincadeiras eram pouco valorizadas. Enquanto na El as crianças brincavam quase todo o dia, no parquinho ou na sala, e Gisele assumia o papel de líder no grupo, no EF só podiam brincar por um tempo determinado nas sextas-feiras e na hora do recreio. Brincar, para esta cultura escolar, indicava crianças ainda imaturas, crianças do jardim de infância. Havendo poucas brincadeiras na escola, Gisele perdeu um espaço valioso para o desenvolvimento de suas significações de si, um lugar no qual ela buscava reconhecimento social, significava e ressignificava seus posicionamentos, desejos, inseguranças e projeções de futuro. Quando o novo contexto estabeleceu novos objetivos a alcançar, exigindo exclusivamente a realização de deveres escolares, o seu sistema de Self passou a construir novas significações com base em novas referências. Se brincar e ser líder das brincadeiras já não era mais uma ferramenta para reafirmar seu papel como sujeito em relação a outros, agora realizar os deveres e tarefas tornou-se o contexto (meio) para que novos significados emergissem e compensassem o que estava sendo perdido (por exemplo, a liderança nas brincadeiras). Desta maneira, surgiu a significação de si "Eu como desenhista". Os indicadores desta significação de si emergiram em uma das entrevistas individuais quando a pesquisadora perguntou a Gisele: "O que você acha que você sabe fazer melhor do que os outros"? Gisele respondeu "Eu sei desenhar muito bem". Ela também era reconhecida pelos seus colegas e professora como "boa desenhista".

A coconstrução da concepção "eu desenhista" foi gerada a partir da internalização feita por Gisele das sugestões (avaliações) de vários adultos na família e na escola sobre sua competência, compatível com as exigências do novo contexto escolar. A professora e a mãe da menina, adultos significativos em sua vida, agiram, assim, como agentes catalisadores da nova posição. No EF sua competência para desenhar ganhou maior destaque e, devido às novas expectativas colocadas pelo contexto, tornou-se uma qualidade central para a geração de significações de si da menina. É possível que, com o tempo, ser "boa desenhista" possa se tornar um signo que alavancará seu desenvolvimento.

A transição da El para o EF representa para Gisele um momento crucial, no qual elaborações psicológicas sobre si mesma e sobre o que ela é e pode vir a ser estão permeadas de sentimentos intensos. Diversos CASs se reconfiguraram no sentido da transformação e equilíbrio (desenvolvimento) do sistema de Self de Gisele. Novas significações de si passaram a alimentar a dinâmica no interior de seus CASs. Evidenciamos conflitos e "opostos" aparentes, capazes de levar à síntese de novos sentidos no Self dialógico.

\section{Ser versus não ser amada}

"Ser versus não ser amada" parece ser o campo caracterizado pela ambivalência mais acentuada na vida de Gisele. Existe um conflito entre sentir-se amada pela sua família e ao mesmo tempo sentir-se desqualificada por não cumprir com as expectativas de ser uma criança bonita e com desempenho acadêmico superior, como a sua irmã. A tensão que ocorria nesse CAS teve efeitos sobre outros CASs, aumentando a ambivalência e a insegurança do sistema de Self. A mudança de um contexto educacional para outro exige que a criança assuma posicionamentos diante de um novo sistema de regras e a confronta com as concepções sobre si mesma, gerando mudanças na dinâmica do sistema de Self em direção à síntese de novas relações entre os CASs. Por exemplo, os CASs inteligente e bonita encontram-se integrados a um sistema mais amplo (Self dialógico), que tem como base a cultura. Assim, a partir das sugestões sociais e da internalização ativa de Gisele das mensagens dos outros significativos, a menina pode se sentir mais ou menos aceita, mais ou menos amada pelos outros por ser bonita e/ou inteligente. $\mathrm{Na}$ escola, suas expressões de afeto com as pessoas a seu redor eram frequentes, ela se colocando como carente de atenção do grupo de 
pares e dos adultos. Ao se colocar como "mais bonita e/ou inteligente", parece que os outros sociais mais próximos (família, professora, colegas de sala) a valorizam, fazendo com que Gisele se sinta amada, pelo menos esta parece ser a compreensão da menina. As desqualificações do pai sobre seu desempenho acadêmico em contraposição com as sugestões da escola ("Você é boa, você sabe sim") são internalizadas por Gisele, criando questionamentos sobre a aceitação dos outros e levando-a a esforçar-se continuamente para ganhar o carinho e o afeto, especialmente do pai. Assim, os CAS, em sua dinâmica relacional, integram elementos das sugestões sociais e das expectativas de Gisele sobre si mesma, e é esta dinâmica entre os CASs que regula muitos dos comportamentos da menina no dia a dia.

\section{CONSIDERAÇOES FINAIS}

O presente artigo teve como propósito contribuir com o estudo do desenvolvimento do Self na infância com base na intersecção de duas teorias, a Sociocultural Construtivista e a Teoria do Self Dialógico (Hermans, 2001; Branco \& Valsiner, 2012; Valsiner, 2007/2012). Ultimamente autores da área têm ressaltado a importância de estudar o Self na infância em seu caráter dinâmico e sistêmico (Bertau, Gonçalves \& Raggatt, 2012; Gratier \& Bertau, 2012), convidando a uma mudança de perspectiva de um Self autônomo para um Self relacional, cujos desenvolvimentos e mudanças dependem da alteridade (Bertau et al. 2012). Assim, no processo de transição desenvolvimental estudado identificamos aspectos importantes da dinâmica, como mudanças e a emergência de significações sobre si no sistema de Self dialógico da criança, o que acreditamos haver contribuído para o enriquecimento do corpus empírico e teórico das abordagens antes mencionadas. A formulação de CAS para estudar os processos de significação resultou em uma estratégia útil para analisar as interações entre os recursos intrapsicológicos da criança e as sugestões da cultura, ou seja, a intersecção entre cultura pessoal e cultura coletiva (Valsiner, 2007/2012) em seu movimento dialógico. Como propõe Bertau (2102), o Self se desenvolve na zona de contato entre o sujeito e a cultura. Assim, ao longo do desenvolvimento global do individuo podem ocorrer ciclos de produção, inovação ou manutenção de significados sobre si à medida que as interações sujeito-cultura ocorrem no tempo irreversível.

Em estudo recente com adolescentes e jovens, Mattos (2013) encontrou resultados coerentes com a abordagem aqui adotada, segundo a qual existe uma interdependência entre os CASs nos quais são formadas zonas de tensão afetivo-semiótica que se alteram conforme 0 sujeito se relaciona com os diferentes contextos de desenvolvimento. A tensão que se cria e se estabelece entre os CASs constitui o principal fator que produz a mudança e o desenvolvimento do sujeito ao longo dos tempos micro, meso e ontogenético (Valsiner, 2007/ 2012). As relações hierárquicas entre os CASs dependem da mediação semiótica, dos diferentes níveis de generalização dos significados ao longo do tempo, da carga afetiva que os outros e o sujeito imprimem nas interações e do contexto cultural onde o individuo está inserido. Assim, é a partir da forte tensão afetivo-semiótica que o sistema de Self se desenvolve, e quanto mais forte for esta tensão, devido a um alto grau de ambivalência, mais nítidos são os indicadores da existência dos campos em aparente oposição dialética.

Assumimos que o sistema de Self dialógico só pode se desenvolver a partir da interação do sujeito com a cultura e com os outros. Assim, a análise da criança nas suas interações sociais permite a compreensão de como se dá o processo de desenvolvimento do Self. Consideramos ainda, que no processo de transição as crianças fazem reflexões e avaliações sobre si mesmas, produzindo indicadores emocionais e de comportamento que sugerem a dinâmica de seu sistema de Self em desenvolvimento.

Para finalizar - em nossa avaliação, este estudo de caso é uma ilustração dos embates vividos na infância e dos questionamentos feitos por uma criança sobre si mesma, já desde muito cedo. Conseguimos evidenciar múltiplas ambivalências e tensões que apareceram no percurso de um ano, diante dos desafios que impulsionam seu desenvolvimento. A partir das análises, verificamos que os adultos (pais, professores) podem se constituir em importantes agentes catalisadores dos processos de desenvolvimento, e que as suas palavras e ações, com forte carga afetiva, provocam um impacto profundo nas significações que a 
criança faz sobre si mesma. Destacamos, em especial, o papel da escola e das professoras da menina, pois constatamos quanto o espaço educativo representa um cenário central de coconstrução e reconstrução de sentidos e significados que enriquecem - ou empobrecem o desenvolvimento do Self.

Concluímos que criança deve estar no centro do processo educativo e ser pensada como um sujeito complexo, em permanente transformação. Ela está inserida em contextos culturais que orientam seu curso de vida e atuam como importante agente de seu desenvolvimento. É relevante destacar, também, que aquilo que os adultos comunicam e metacomunicam sobre ela e para ela é marcado por forte carga afetiva e, consequentemente, tem um importante impacto em seu desenvolvimento subjetivo.

\section{Agradecimentos}

As pesquisadoras deste trabalho gostariam agradecer a Gisele, seus pais e sua irmã, bem como às instituições de El e EF que abriram as portas para a realização desta pesquisa; e também à CAPES, que financiou os estudos doutorais da primeira autora.

\section{REFERÊNCIAS}

Amaral, C. (2008). O que é ser criança e viver a infância na escola: uma análise da transição da educação infantil para o ensino fundamental numa escola municipal de Curitiba. Dissertação de Mestrado Não-Publicada, Programa de Pós-Graduação em Psicologia, Universidade Federal do Paraná, Paraná.

Bertau, M. C. (2012). Exploring voice: A psycholinguist's inquiry into the Dynamic Materiality of language. In M. C. Bertau, M. M. Gonçalves \& P. Raggatt (Eds.), Dialogic formations: Investigations into the origins and development of the dialogical self (pp. 41-68). Charlotte, NC: Information Age Publishing Inc.

Bertau, M. C., Gonçalves, M., \& Raggatt, P. (2012). Dialogic formations: Investigations into the origins and development of the dialogical self. Charlotte, NC: Information Age Publishing Inc.

Branco, A. U. (2010). Dialogical self conceptualizations along the dynamics of cultural canalizations processes of self development. Trabalho apresentado em 6th Dialogical Self Conference, Atenas, Grécia.

Branco, A. U. \& Mettel, T. P. L (1995). O processo de canalização cultural das interações criança-criança na préescola. Psicologia: Teoria e Pesquisa, 11(1), 13-22.

Branco, A. U., \& Valsiner, J. (1997). Changing methodologies: A co-constructivist study of goal orientation in social interaction. Psychology and Developing Societies, 9(1), 3564.

Branco, A. U., \& Valsiner, J. (2004). Communication and metacommunication in human development. Greenwich, CT: Information Age Publishing Inc.

Branco, A. U., \& Valsiner, J. (2012). Cultural psychology of human values. Charlotte, NC: Information Age Publishing Inc.

Branco, A. U., Branco, A. L., \& Madureira, A. F. (2008). Selfdevelopment and the emergence of new I-positions: Emotions and self-dynamics. Studia Psychologica (Bratislava), 8, 23-40.

Bruner, J. (1997). Atos de significação. (S. Costa, Trad.) Porto Alegre: ArtMed. (Original publicado em 1990).

Corsaro, W.A., \& Molinari, L. I. (2005). Understanding children's transition from preschool to elementary school. New York: Teachers College Press.

Ferraz, S. (2008). Concepções Dinâmicas de Si de crianças em escolarização: uma perspectiva dialógicodesenvolvimental. Tese de Doutorado não publicada, Instituto de Psicologia, Universidade de Brasília.

Ford, D. H., \& Lerner, R. M. (1992). Developmental systems theory: An integrative approach. Newbury Park, CA: Sage.

Gratier, M., \& Bertau, M. C. (2012). Polyphony: A vivid source of self and symbol. In M.C. Bertau, M. M. Gonçalves \& P. Raggatt (Eds.), Dialogic Formations: Investigations into the origins and development of the dialogical self (pp. 85-120). Charlotte, NC: Information Age Publishing Inc.

Hermans, H. J. M. (2001). The dialogical self: Toward a theory of personal and cultural positioning. Culture \& Psychology, 7, 243-281.

Hermans, H. J. M., \& Hermans-Konopka, A. (2010). Dialogical self theory: positioning and counter-positioning in a globalizing society. New York: Cambridge University Press.

Mattos, E. (2013). Desenvolvimento do self na transição para a vida adulta: um estudo longitudinal com jovens baianos. Tese de Doutorado Não-Publicada, Programa de PósGraduação em Psicologia, Universidade Federal da Bahia, Bahia.

Mead, G. H. (1934). Mind, self, and society. Chicago: University of Chicago Press.

Motta, F., \& Kramer, S. (2010). De Crianças a Alunos: Transformações Sociais na Passagem da Educação Infantil para o Ensino Fundamental. Tese de Doutorado Não-Publicada, Departamento de Educação, Pontifícia Universidade Católica do Rio de Janeiro, Rio de Janeiro.

Rogoff, J. (2005). A natureza cultural do desenvolvimento humano. (R. Cataldo, Trad.). Porto Alegre: ArtMed. (Original publicado em 2003).

Valsiner, J. (2012). Fundamentos de psicologia cultural: mundos da mente, mundos da vida. (A. Bastos, Trad.). Porto Alegre: Artmed. (Original publicado em 2007).

Valsiner, J., \& Salvatore, S. (2012). How idiographic science could create its own terminology. In S. Salvatore, A. Gennaro \& J. Valsiner (Eds.), Making Sense of Infinite Uniqueness (pp. 3-20). Charlotte, NC: Information Age Publishing, INC.

Zittoun, T. (2009). Dynamics of life-course transitions - a methodological reflections. In J. Valsiner. P. C. M. 
Molenaar, M. C.D.P. Lyra \& N. Chaudhary (Eds.), Dynamic

Process Methodology in the Social and Developmental Sciences (pp. 405-430). New York: Springer.

Monica Roncancio Moreno: mestre em Psicologia pela Universidad del Valle, Colômbia, doutoranda em Psicologia no Programa Processos de desenvolvimento humano e saúde da Universidade de Brasília; professora da Universidad Javeriana, Bogotá, Colômbia.

Angela Maria Branco: mestre em Psicologia pela Universidade de Brasília, doutora em Psicologia pela Universidade de São Paulo, estudos pós-doutorais na University of North Carolina, na Duke University, na Clark University e na Universidad Autónoma de Madrid; professora no Instituto de Psicologia da Universidade de Brasília. 